\title{
Accumulation of Sulphite by Saccharomyces cerevisiae and Zygosaccharomyces bailii as Affected by Phospholipid Fatty-acyl Unsaturation and Chain Length
}

\author{
By BRIDGET J. PILKINGTON AND ANTHONY H. ROSE* \\ Zymology Laboratory, School of Biological Sciences, Bath University, Bath, Avon BA2 7AY, UK
}

(Received 27 January 1989; revised 25 April 1989; accepted 6 June 1989)

Analyses were made of the fatty-acyl composition of phospholipids from each of two strains of Saccharomyces cerevisiae and Zygosaccharomyces bailii grown aerobically. Residues of $\mathrm{C}_{16: 0}$, $\mathrm{C}_{16: 1}$ and $\mathrm{C}_{18: 1}$ predominated in phospholipids from strains of the first yeast, while phospholipids from $Z$. bailii contained mainly $\mathrm{C}_{16: 0}, \mathrm{C}_{18: 1}$ and $\mathrm{C}_{18: 2}$ residues. $S$. cerevisiae NCYC 431, grown anaerobically in media supplemented with ergosterol and $C_{14: 1}, C_{16: 1}, C_{18: 1}$, $\mathrm{C}_{18: 2}, \mathrm{C}_{18: 3}$ or $\mathrm{C}_{20: 1}$ fatty acids, contained phospholipids enriched with residues of the exogenously provided acid, to a greater extent with shorter chain than longer chain acids. A plot of the permeability coefficient for sulphite, derived from Woolf-Eadie plots, against the degree of unsaturation in phospholipids (expressed as $\Delta \mathrm{mol}^{-1}$ value) showed that the coefficient was greater the lower the degree of unsaturation in the phospholipids. A plot of the permeability coefficient against values for the mean fatty-acyl chain length divided by the $\Delta \mathrm{mol}^{-1}$ value, which is an approximation of the cross-section surface area of a phospholipid molecule, showed that the permeability coefficient tended to increase the greater the surface-area value.

\section{INTRODUCTION}

Sulphite, a powerful antimicrobial agent (Hammond \& Carr, 1976), exists in solution in three forms, the proportions of which depend on the $\mathrm{pH}$ value. At $\mathrm{pH}$ values below 1.8, sulphite exists predominantly as free $\mathrm{SO}_{2}$ and at $\mathrm{pH}$ values above 7.2 largely as $\mathrm{SO}_{3}^{2-}$; at intermediate $\mathrm{pH}$ values, it exists in various proportions as $\mathrm{HSO}_{3}^{-}$(King et al., 1981). The antimicrobial action of sulphite is greatest in solutions at low pH values (Wedzicha, 1984), which explains why the compound is particularly effective against yeasts which, in general, grow best at $\mathrm{pH}$ values in the range 3.0-5.0 (Rose, 1987). Of the three forms in which sulphite exists in solution, only $\mathrm{SO}_{2}$ has been shown to enter strains of Saccharomyces cerevisiae, Saccharomycodes ludwigii (Stratford \& Rose, 1986; Stratford et al., 1987) and Zygosaccharomyces bailii (Pilkington \& Rose, 1988), in all cases by free diffusion. Yeast species differ considerably in their ability to grow in the presence of sulphite. Kloeckera apiculata and Hansenula anomala were reported by Warth (1985) to be more sensitive to the compound than strains of $S$. cerevisiae. Other sulphite-resistant yeasts which have been described include strains of $S^{\prime}$ codes ludwigii (Stratford et al., 1987) and Z. bailii (Thomas \& Davenport, 1985; Pilkington \& Rose, 1988). Differences in sulphite resistance among yeast species have been attributed, in part, to variations in their ability to produce sulphite-binding compounds, particularly acetaldehyde, when grown in the presence of the antimicrobial compound (Rankine, 1968; Rankine \& Pocock, 1969; Pilkington \& Rose, 1988). It has also been suggested (Stratford et al., 1987) that variations in sulphite resistance among yeast species might be partly attributable to differences in ability to accumulate the compound. The present paper reports on the effect of phospholipid fatty-acyl unsaturation and chain length on the ability of strains of $S$. cerevisiae and $Z$. bailii to accumulate sulphite. 


\section{METHODS}

Organisms. The yeasts used were $S$. cerevisiae NCYC 431, S. cerevisiae TC8 (Stratford \& Rose, 1985), Z. bailii NCYC 563 and Z. bailii NCYC 1427 (Pilkington \& Rose, 1988). The strains were maintained at $4{ }^{\circ} \mathrm{C}$ on slopes of malt extract-yeast extract-glucose-mycological peptone (MYGP) agar (Wickerham, 1951).

Experimental cultures. Organisms were grown aerobically in medium containing $\left(1^{-1}\right)$ : glucose, $20 \mathrm{~g}$; $\left(\mathrm{NH}_{4}\right)_{2} \mathrm{SO}_{4}, 3.0 \mathrm{~g} ; \mathrm{KH}_{2} \mathrm{PO}_{4}, 3.0 \mathrm{~g}$; yeast extract (Lab M), $1.0 \mathrm{~g} ; \mathrm{CaCl}_{2} .2 \mathrm{H}_{2} \mathrm{O}, 30 \mathrm{mg} ;$ and $\mathrm{MgSO}_{4} .7 \mathrm{H}_{2} \mathrm{O}, 30 \mathrm{mg}$ (adjusted to pH 4.0 with $\mathrm{HCl}$ ). Portions of medium (11) were dispensed into 21 round flat-bottomed flasks which were plugged with cotton wool and sterilized by autoclaving at $6.89 \times 10^{4} \mathrm{~Pa}$ for $10 \mathrm{~min}$. Starter cultures $(100 \mathrm{ml}$ medium in $250 \mathrm{ml}$ conical flasks) were inoculated with a pinhead of yeast from a slant culture and incubated at $30^{\circ} \mathrm{C}$ for $24 \mathrm{~h}$ on an orbital shaker (200 r.p.m.). Portions of medium (1 l) were inoculated with portions of starter culture containing $0.05 \mathrm{mg}$ dry wt $S$. cerevisiae NCYC $431,0.5 \mathrm{mg}$ dry wt $S$. cerevisiae TC8 or $1.0 \mathrm{mg}$ dry wt of either of the $Z$. bailii strains. Experimental cultures were incubated at $30^{\circ} \mathrm{C}$ with stirring by a magnetic stirrer bar (50 mm length) (Patching \& Rose, 1970). Organisms were grown anaerobically by a modification of the method of Alterthum \& Rose (1973) in medium containing (1-1): glucose, $50 \mathrm{~g} ; \mathrm{KH}_{2} \mathrm{PO}_{4}, 4.5 \mathrm{~g} ;\left(\mathrm{NH}_{4}\right)_{2} \mathrm{SO}_{4}, 3.0 \mathrm{~g} ;$ yeast extract ( $\mathrm{Lab} \mathrm{M}$ ), $1 \mathrm{~g} ; \mathrm{CaCl}_{2} \cdot 2 \mathrm{H}_{2} \mathrm{O}, 25 \mathrm{mg}$; and $\mathrm{MgSO}_{4} \cdot 7 \mathrm{H}_{2} \mathrm{O}, 25 \mathrm{mg}$ (adjusted to $\mathrm{pH} 4.0$ with $\mathrm{HCl}$ ). Portions of medium (1 l) were dispensed into 21 round flat-bottomed flasks and sterilized as already described. Anaerobic conditions were maintained throughout growth by flushing the flasks with high-purity nitrogen gas from which the last traces of oxygen had been removed by passage through an Oxy-trap column (Alltech Associates). Prior to inoculation, the medium was supplemented with ergosterol $\left(5 \mathrm{mg}^{-1}\right)$ and myristoleic acid $\left(\mathrm{C}_{14: 1} \Delta^{9}\right)$, palmitoleic acid $\left(C_{16: 1} \Delta^{9}\right)$, oleic acid $\left(C_{18: 1} \Delta^{9}\right)$, linoleic acid $\left(C_{18: 2} \Delta^{9,12}\right), \alpha$-linolenic acid $\left(C_{18: 3} \Delta^{9,12,15}\right)$ or 11-eicosenoic acid $\left(C_{20: 1} \Delta^{11}\right)$ (all $30 \mathrm{mg} \mathrm{ml}^{-1}$ ). Portions of medium were inoculated with $1 \mathrm{mg}$ dry wt organism from an overnight starter culture of $S$. cerevisiae NCYC 431 and incubated as previously described. Control cultures lacking an unsaturated fatty acid were incubated with each batch of experimental cultures. When growth in the control exceeded $0.1 \mathrm{mg}$ dry wt $\mathrm{ml}^{-1}$, experimental cultures were discarded. Growth of aerobic and anaerobic cultures was followed by measuring the optical density at $600 \mathrm{~nm}$ of portions of culture, measurements being related to the dry wt of organisms by a standard curve constructed for each strain of yeast. Organisms were harvested from midexponential phase cultures containing $0.5 \mathrm{mg}$ dry wt $S$. cerevisiae $\mathrm{ml}^{-1}$ or $0.25 \mathrm{mg}$ dry wt $Z$. bailii ml $\mathrm{ml}^{-1}$ by filtration through a membrane filter $(0.45 \mu \mathrm{m}$ pore size; $50 \mathrm{~mm}$ diam.; Oxoid $)$ or by centrifugation $\left(6000 \mathrm{~g}, 1 \mathrm{~min}, 4^{\circ} \mathrm{C}\right)$ and washed as indicated.

Measurement of velocity of sulphite accumulation. To measure initial velocities $(v)$ of sulphite accumulation, organisms were washed twice with $30 \mathrm{~mm}$-sodium citrate buffer ( $\mathrm{pH} 3.0$ ) containing $100 \mathrm{~mm}$-glucose, suspended in the same buffer at $10 \mathrm{mg} \mathrm{dry} \mathrm{wt} \mathrm{ml}^{-1}$ and the suspension allowed to equilibrate for $3 \mathrm{~min}$ at $30^{\circ} \mathrm{C}$. A reaction mixture consisting of $30 \mathrm{mM}$-citrate buffer ( $\mathrm{pH} \mathrm{3.0)}$ containing $100 \mathrm{mM}$-glucose and $10-200 \mu \mathrm{M}-\left[{ }^{35} \mathrm{~S}\right] \mathrm{sulphite}$ $\left(0.20 \mu \mathrm{Ci} \mathrm{ml} l^{-1} ; 1 \mu \mathrm{Ci}=37 \mathrm{KBq} ; s\right)$ was prepared in a Universal bottle and warmed to $30^{\circ} \mathrm{C}$ in a water-bath. . Labelled sulphite was stored at $-20^{\circ} \mathrm{C}$ in 5 mM-EDTA under nitrogen gas in $0.5 \mathrm{ml}$ samples $\left(0.1 \mathrm{mCi} \mathrm{ml}^{-1}\right)$ to prevent oxidation. Portions $(300 \mu \mathrm{l})$ of the suspension of organisms were dispensed into microcentrifuge tubes (Eppendorf). Using a $1.5 \mathrm{ml}$ multi-dispense syringe pipette, $1.25 \mathrm{ml}$ of labelled sulphite reaction mixture was added to the suspension which was quickly mixed by refilling and emptying the syringe. Uptake of ${ }^{35} \mathrm{~S}$ was linear up to at least $8 \mathrm{~s}$. After $4 \mathrm{~s}, 1.5 \mathrm{ml}$ of the suspension was rapidly filtered through a membrane filter $(0.45 \mu \mathrm{m}$ pore size; $25 \mathrm{~mm}$ diam.; Millipore) which had been washed with $5 \mathrm{ml} 10 \mathrm{~mm}$-sulphite in $30 \mathrm{~mm}$-citrate buffer (pH 3.0). After filtration, three $1 \mathrm{ml}$ portions of buffered sulphite solution of the same concentration as emplo ed in the experiment were used quickly to wash the organisms and filter. Filters with organisms were then placed in scintillation vials containing $7 \mathrm{ml}$ Optiphase Safe (Fisons). Radioactivity in the vials was measured in an LKB Rackbeta liquid scintillation spectrometer (model 1217).

Lipid analysis. Organisms ( $250 \mathrm{mg}$ dry wt) were washed with water and mixed with $10 \mathrm{ml} 80 \%(\mathrm{v} / \mathrm{v})$ ethanol in a Universal bottle and heated at $80^{\circ} \mathrm{C}$ for $15 \mathrm{~min}$ in a water-bath to deactivate lipolytic enzymes and to split lipidprotein linkages (Letters, 1968). The extract was filtered through Whatman no. 44 filter paper and the filtrate stored at $-20^{\circ} \mathrm{C}$ while the residue was extracted twice with chloroform/methanol $(2: 1, \mathrm{v} / \mathrm{v})$ for 2 and $1 \mathrm{~h}$, respectively, as it was stirred magnetically on a flat-bed stirrer at room temperature. The three filtrates were pooled, washed with $0.25 \mathrm{vol} .0 \cdot 88 \% \mathrm{KCl}$ and the mixture left to separate overnight at $-20^{\circ} \mathrm{C}$. The lower organic phase was removed, taken to dryness using a rotary evaporator, and the residue dissolved in $1 \mathrm{ml}$ light petroleum (b.p. $60-80^{\circ} \mathrm{C}$ ). Extracts, stored if necessary under nitrogen gas at $-20^{\circ} \mathrm{C}$, were evaporated under a stream of nitrogen gas until approximately $100 \mu \mathrm{l}$ remained and streaked onto a $20 \times 20 \mathrm{~cm} 0.25 \mathrm{~mm}$ Silica Gel 60 TLC plate (Merck). On the same plate were streaked phosphatidylethanolamine, ergosterol or palmitic acid standards [all 1 $\mathrm{mg} \mathrm{ml}^{-1}$ in light petroleum (b.p. $60-80^{\circ} \mathrm{C}$ )]. The plate was developed in a light petroleum (b.p. $40-60^{\circ} \mathrm{C}$ )/diethyl ether/acetic acid $\left(70: 30: 1\right.$, by vol.) solvent mixture and lipids located by spraying with $0 \cdot 2 \%(\mathrm{w} / \mathrm{v}) 2^{\prime}, 7^{\prime}-$ dichlorofluorescein in ethanol and viewed under UV $(254 \mathrm{~nm})$ radiation. The area containing the phospholipid fraction on the plate was scraped off and transferred to a $5 \mathrm{ml}$ screw-top vial. 
To analyse the fatty-acyl composition of the phospholipid fraction, samples were methylated by refluxing with 3 $\mathrm{ml} \mathrm{BF}_{3}(14 \%$, w/v, in methanol $)$ for $1 \mathrm{~h}$ at $80^{\circ} \mathrm{C}$ in sealed vials. After cooling, each sample was added to $5 \mathrm{ml}$ water in stoppered glass tubes, supplemented with $3 \mathrm{ml}$ light petroleum (b.p. $60-80^{\circ} \mathrm{C}$ ) and shaken vigorously. Fattyacid methyl esters were extracted into the light petroleum. This extraction procedure was repeated twice more, the extracts pooled and stored under nitrogen gas at $-20^{\circ} \mathrm{C}$. Fatty-acid methyl esters were analysed using a fused capillary column ( $25 \mathrm{~m}$ length; SGE BP 21 ) in a Pye Unicam GCD chromatograph fitted with an SGE on-column adaptor. The injection temperature was $250^{\circ} \mathrm{C}$, and the column maintained at $110^{\circ} \mathrm{C}$ for the first $5 \mathrm{~min}$, after which it was raised at the rate of $8{ }^{\circ} \mathrm{C} \mathrm{min}{ }^{-1}$ until it reached $180^{\circ} \mathrm{C}$. The carrier gas was hydrogen flowing at $6 \mathrm{ml}$ $\mathrm{min}^{-1}$. Percentage fatty-acyl compositions were calculated using an LDC/Milton Roy integrator.

Chemicals. All reagents used were AnalaR or of the highest grade available commercially. Amersham supplied ${ }^{35}$ S $]$ sulphite.

\section{RESULTS}

\section{Fatty-acyl composition of phospholipids}

The principal fatty-acyl residue in phospholipids from aerobically grown strains of $S$. cerevisiae was $C_{16: 1}$, followed by $C_{18: 1}$ and $C_{16: 0}$ (Table 1 ). In both strains of $Z$. bailii, $C_{18: 2}$ was the major fatty-acyl residue in their phospholipids, followed by $C_{18: 1}$ and $C_{16: 0}$ (Table 1). Neither strain of $Z$. bailii grew anaerobically while $S$. cerevisiae TC8 grew anaerobically to some extent in lipid-free medium, and therefore could not be used to provide organisms enriched in specific fatty-acyl residues. $S$. cerevisiae NCYC 431 was therefore used to study the manner in which sulphite transport was affected by the composition of the unsaturated fatty-acyl residues in cellular phospholipids. Organisms grown in the presence of $C_{14: 1}$ and $C_{16: 1}$ fatty acids were enriched in residues of these acids to the greatest extent (Table 2). Enrichment with $C_{18: 1}, C_{18: 2}$ and $\mathrm{C}_{18: 3}$ residues was to a lesser extent, while that with $\mathrm{C}_{20: 1}$ residues was a mere $13 \%$.

\section{Effect of fatty-acyl unsaturation and chain length on permeation of sulphite}

Since permeation of sulphite will depend upon membrane surface area, initial velocities of sulphite accumulation were calculated as nmol mm $\mathrm{mm}^{-2} \mathrm{~min}^{-1}$ (Pilkington \& Rose, 1988). WoolfEadie plots ( $v$ against $v s^{-1}$; Hofstee, 1959) of initial rates of sulphite accumulation by all four yeast strains yielded vertical plots. The value for $v s^{-1}$ on the vertical section gave a measure of the permeability coefficient of sulphite for the yeast strain (Laidler, 1977). A plot of the

Table 1. Fatty-acyl composition of phospholipids from aerobically grown strains of $S$. cerevisiae and $Z$. bailii

Values quoted are the means of three independent determinations \pm SD. tr., A trace of the residue was detected; -, no trace was detected. Values for unsaturation $\left(\Delta \mathrm{mol}^{-1}\right)$ were calculated as described by Kates \& Hagen (1964).

Percentage of the total fatty-acyl content in phospholipids from:

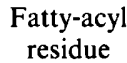

$8: 0$

10:0

$12: 0$

$14: 0$

$14: 1$

$16: 0$

$16: 1$

$18: 0$

$18: 1$

$18: 2$

$\Delta \mathrm{mol}^{-1}$

$\overbrace{\text { NCYC } 431}^{\text {S. cerevisiae }}$

tr.

$1 \cdot 3 \pm 0 \cdot 2$

$1.4 \pm 0.2$

$4.1 \pm 0.4$

$1.3 \pm 0.3$

$16.2 \pm 0.8$

$52.3 \pm 1.7$

$1.9 \pm 0.2$

$20.3 \pm 1 \cdot 0$

0.74
$0.7 \pm 0.3$

$2.2 \pm 0.2$

tr.

$17 \cdot 3 \pm 0 \cdot 3$

$46.4 \pm 1 \cdot 7$

$2.7 \pm 0.3$

$30.0 \pm 1.5$

0.77

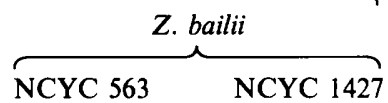

NCYC 1427

$\begin{array}{rc}- & - \\ - & \text { tr. } \\ - & \text { tr. } \\ 11 \cdot 1 \pm 3.0 & 14.7 \pm 0.7 \\ 9.9 \pm 1.9 & 12.2 \pm 2.2 \\ 7.5 \pm 1.5 & 6.1 \pm 1 \cdot 1 \\ 33.0 \pm 1.6 & 29.6 \pm 2.6 \\ 38.4 \pm 2.8 & 41.2 \pm 3.6 \\ 1.13 & 1.24\end{array}$




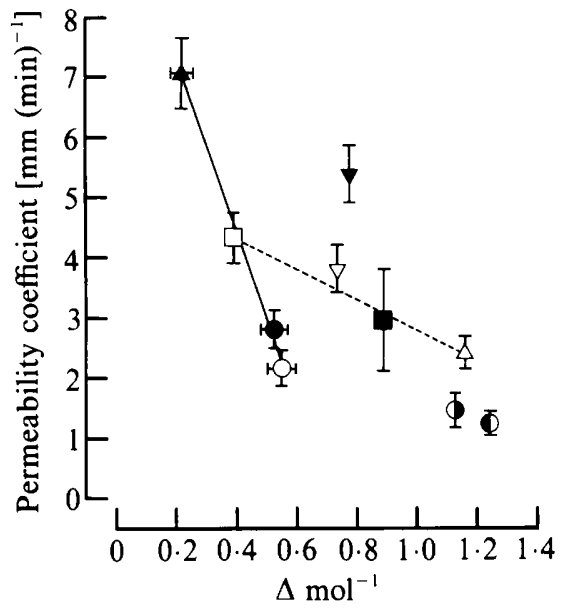

Fig. 1

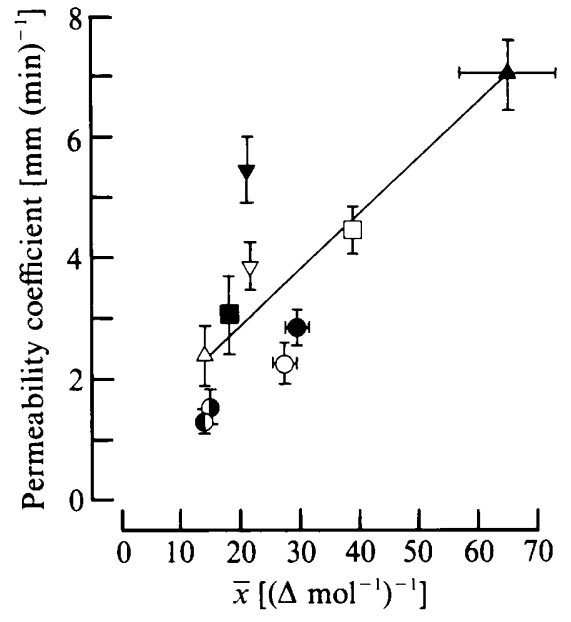

Fig. 2

Fig. 1. Relationship between the permeability coefficient for $\mathrm{SO}_{2}$ and the $\Delta \mathrm{mol}^{-1}$ values for phospholipids from $S$. cerevisiae NCYC 431 grown anaerobically in the presence of $C_{14: 1}(O), C_{16: 1}$ $(\bigcirc), C_{18: 1}(\square), C_{18: 2}(\square), C_{18: 3}(\triangle)$ and $C_{20: 1}(\Delta)$ fatty acids. The relationship is also shown for aerobically grown $S$. cerevisiae NCYC $431(\nabla), S$. cerevisiae TC8 $(\nabla), Z$. bailii NCYC $563(O)$ and $Z$. bailii NCYC 1427 (D). Values for the permeability coefficients were calculated from Woolf-Eadie plots as described in the text, and $\Delta \mathrm{mol}^{-1}$ values as described by Kates \& Hagen (1964).

Fig. 2. Relationship between the permeability coefficient for $\mathrm{SO}_{2}$ and values for mean chain lengths of cellular phospholipids $(\bar{x})$ divided by the $\Delta \mathrm{mol}^{-1}$ value for phospholipids. The relationship is shown for the yeast strains listed in the legend to Fig. 1, and grown under the conditions described there. The Fig. 1 legend indicates how values for the permeability coefficient and $\Delta \mathrm{mol}^{-1}$ were calculated.

\section{Table 2. Fatty-acyl composition of phospholipids from S. cerevisiae NCYC 431 grown anaerobically in media supplemented with different fatty acids}

Values quoted are the means of three independent determinations $\pm \mathrm{SD}$. tr., A trace of the residue was detected; -, no trace was detected. Values for unsaturation $\left(\Delta \mathrm{mol}^{-1}\right)$ were calculated as described by Kates \& Hagen (1964).

Percentage of total fatty-acyl content

Fatty-acyl

\begin{tabular}{|c|c|}
\hline \multicolumn{2}{|c|}{ Percentage of total fatty-acyl content } \\
\hline \multicolumn{2}{|c|}{ Fatty acid supplement : } \\
\hline$C_{14: 1}$ & $\mathrm{C}_{16: 1}$ \\
\hline
\end{tabular}

residue

\begin{tabular}{|c|c|c|c|c|c|c|}
\hline $8: 0$ & - & - & - & - & - & $4.0 \pm 0.5$ \\
\hline $10: 0$ & tr. & $3 \cdot 1 \pm 1 \cdot 3$ & $7.8 \pm 3.8$ & $5.9 \pm 3.4$ & $4 \cdot 6 \pm 2 \cdot 7$ & $16 \cdot 1 \pm 1.6$ \\
\hline $12: 0$ & tr. & $4.4 \pm 1 \cdot 3$ & $7.8 \pm 2.4$ & $4.7 \pm 2.6$ & $4.8 \pm 1.9$ & $17 \cdot 5 \pm 1 \cdot 5$ \\
\hline $14: 0$ & $3.8 \pm 1.9$ & $7 \cdot 2 \pm 1 \cdot 1$ & $15 \cdot 1 \pm 2 \cdot 4$ & $9.8 \pm 2.4$ & $9.8 \pm 2.4$ & $13.4 \pm 1.4$ \\
\hline $14: 1$ & $52.4 \pm 2.0$ & tr. & tr. & - & - & $2.1 \pm 0.6$ \\
\hline $16: 0$ & $34 \cdot 0 \pm 2 \cdot 0$ & $28 \cdot 1 \pm 1.7$ & $28.0 \pm 3.6$ & $32 \cdot 9 \pm 1 \cdot 1$ & $35.7 \pm 1.4$ & $22.9 \pm 1.6$ \\
\hline $16: 1$ & $2 \cdot 1 \pm 0.3$ & $52 \cdot 1 \pm 6 \cdot 1$ & $3.7 \pm 1.6$ & $1 \cdot 1 \pm 0.6$ & $0.7 \pm 0.4$ & $6.6 \pm 2.5$ \\
\hline $18: 0$ & $5.6 \pm 1.0$ & $4.7 \pm 1 \cdot 1$ & tr. & $4.9 \pm 1.6$ & $5 \cdot 2 \pm 1 \cdot 2$ & $2.8 \pm 1.4$ \\
\hline $18: 1$ & tr. & tr. & $35 \cdot 6 \pm 6 \cdot 0$ & - & - & $1.5 \pm 0.5$ \\
\hline $18: 2$ & - & - & - & $40.9 \pm 6.8$ & - & - \\
\hline $18: 3$ & - & - & - & - & $38 \cdot 2 \pm 5.9$ & - \\
\hline $20: 1$ & - & - & - & - & - & $13 \cdot 1 \pm 5.6$ \\
\hline$\Delta \mathrm{mol}^{-1}$ & 0.55 & 0.53 & 0.40 & 0.90 & $1 \cdot 16$ & 0.22 \\
\hline
\end{tabular}

permeability coefficient against the $\Delta \mathrm{mol}^{-1}$ value for permeation of sulphite by all four yeast strains showed that the value for the coefficient was greater the lower the $\Delta \mathrm{mol}^{-1}$ value (Fig. 1). Values for the permeability coefficient and $\Delta \mathrm{mol}^{-1}$ were linearly related for $S$. cerevisiae NCYC 431 enriched in residues of $C_{14: 1}, C_{16: 1}, C_{18: 1}$ and $C_{20: 1}$, and also for this strain enriched in $C_{18: 1}$, 
$\mathrm{C}_{18: 2}$ and $\mathrm{C}_{18: 3}$ residues (Fig. 1). A plot of permeability coefficient against mean chain length of the phospholipids $(\bar{x})$ divided by the $\Delta \mathrm{mol}^{-1}$ value (Fig. 2) showed that the permeability coefficient tended to increase the greater the value for mean chain length $\left(\Delta \mathrm{mol}^{-1}\right)^{-1}$.

\section{DISCUSSION}

Numerous analyses have been reported on the fatty-acyl composition of whole-cell lipids of strains of aerobically grown $S$. cerevisiae (Rattray, 1988), but hardly any on the fatty-acyl composition of the total phospholipid fraction of lipids from this yeast. The analyses reported in the present paper for the fatty-acyl composition of phospholipids from the two strains examined confirm the conclusions drawn by Rattray (1988) concerning the fatty-acyl composition of whole-cell lipids of aerobically grown $S$. cerevisiae, namely that they are rich in $\mathrm{C}_{16: 1}$ and $\mathrm{C}_{18: 1}$ residues, with $C_{16: 0}$ residues accounting for a minor proportion. When compared with the analyses reported by Rattray (1988) for whole-cell lipids of this yeast, it can be inferred that phospholipids are richer in unsaturated fatty-acyl residues. Just two reports have appeared describing the fatty-acyl composition of whole-cell lipids of $Z$. bailii (Bulder \& Reinink, 1974; Malkhas'yan et al., 1983). Both reports confirm that $Z$. bailii differs from $S$. cerevisiae in being able to synthesize $C_{18: 2}$ fatty-acyl residues. However, our analyses of total phospholipids resemble those of Malkhas'yan et al. (1983) for whole-cell lipids rather than those of Bulder \& Reinink (1974), whose strain was less rich in $C_{18: 2}$ residues. These differences might be attributable to strain differences or to conditions under which the organisms were grown.

Our inability to grow strains of $Z$. bailii under strictly anaerobic conditions, in the presence of lipid supplements, supports the conclusion of Longley et al. (1978) that, among the range of yeast species which they investigated, only $S$. cerevisiae was auxotrophic for lipids when grown under anaerobic conditions. Moreover, the finding that $S$. cerevisiae TC8, unlike $S$. cerevisiae NCYC 431, grew to some extent in medium lacking lipid supplements corroborates the report by David \& Kirsop (1973) that strains of this yeast differ in their affinity for molecular oxygen. The relative extent to which exogenously supplied fatty acids were incorporated into anaerobically grown $S$. cerevisiae NCYC 431 is in general agreement with the results reported by Nes et al. (1984). The very limited incorporation of $C_{20: 1}$ residues, as compared with $C_{18: 1}$ residues, into cellular phospholipids is probably attributable to the inability of these relatively lengthy residues to be accommodated into cellular membranes. It is unlikely that the limited incorporation of $\mathrm{C}_{20: 1}$ residues was caused by an insufficient concentration of this fatty acid in the medium.

In an attempt to explain the greater initial velocity of sulphite accumulation by $S^{\prime}$ codes ludwigii compared with $S$. cerevisiae, Stratford et al. (1987) invoked the increased degree of unsaturation $\left(\Delta \mathrm{mol}^{-1}\right)$ in lipids in the former yeast (Kaneko et al., 1976) arguing that greater membrane fluidity with increased unsaturation might facilitate diffusion of $\mathrm{SO}_{2}$ across the plasma membrane. Data obtained in the present study indicated quite the opposite correlation, namely that a greater value for the permeability coefficient correlated with a low $\Delta \mathrm{mol}^{-1}$ value. The shortcomings of using $\Delta \mathrm{mol}^{-1}$ values as an indicator of the effect of fatty-acyl unsaturation on fluidity in biological membranes are evident. Van der Meer (1984) considered several parameters among which were the cross-section area and volume of phospholipid molecules in a membrane, as well as membrane thickness. The derived value for the mean chain length of fattyacyl residues in membrane lipids $(\bar{x})$ divided by the $\Delta \mathrm{mol}^{-1}$ value can be considered to be related to both the cross-section area of a phospholipid and plasma-membrane thickness. Our data show that the greater this surface-area value, the higher the value for the permeability coefficient. The presence of a double bond in a fatty-acyl chain on a phospholipid molecule causes disorder in the packing of the chain, and consequently to a shortening of the effective mean length of the chains on that phospholipid molecule (Robertson, 1983). The consequent narrowing of the width of the yeast plasma-membrane could explain, at least in part, the correlation between the permeability coefficient and the value for $\bar{x}\left(\Delta \mathrm{mol}^{-1}\right)^{-1}$.

The research reported in this paper was generously supported by AFRC. We also thank Felicity Veazey for assistance with the lipid analyses. 


\section{REFERENCES}

Alterthum, F. \& Rose, A. H. (1973). Osmotic lysis of sphaeroplasts from Saccharomyces cerevisiae grown anaerobically in media containing different unsaturated fatty acids. Journal of General Microbiology 77, 371-382.

Bulder, C. J. E. A. \& ReininK, M. (1974). Unsaturated fatty acid composition of wild type and respiratory deficient yeasts after aerobic and anaerobic growth. Antonie van Leeuwenhoek 40, 445-455.

DAVID, M. H. \& KIRSOP, B. H. (1973). A correlation between oxygen requirements and the products of sterol synthesis in strains of Saccharomyces cerevisiae. Journal of General Microbiology 77, 529-531.

HAMMOND, S. M. \& CARR, J. H. (1976). The antimicrobial activity of $\mathrm{SO}_{2}$ with particular reference to fermented and non-fermented fruit juices. In Inhibition and Inactivation of Vegetative Microbes, pp. 89 110. Edited by F. A. Skinner \& W. B. Hugo. London: Academic Press.

HOFSTEE, B. H. J. (1959). Non-inverted versus inverted plots in enzyme kinetics. Nature, London 184, 12961298.

Kaneko, H., Hosahara, M., Tanaka, M. \& Itoh, T. (1976). Lipid composition of 30 species of yeast. Lipids 11, 837-844.

KATES, M. \& HAGEN, P.-O. (1964). Influence of temperature on fatty acid composition of psychrophilic and mesophilic Serratia spp. Canadian Journal of Biochemistry 42, 481-488.

King, A. D., JR, Ponting, J. D., Sanschuck, D. W., JACKSON, R. \& MIHARA, K. (1981). Factors affecting death of yeast by sulphur dioxide, Journal of Food Protection 44, 92-107.

LAIDLER, K. (1977). Physical Chemistry with Biological Applications. New York: Benjamin Cummings.

LeTTERS, R. (1968). Phospholipids of yeasts. In Aspects of Yeast Metabolism, pp. 303-319. Edited by A. K. Mills. Oxford: Blackwell Scientific Publications.

Longley, R. P., Denniss, R. R., Heyer, M. S. P. \& WREN, J. J. (1978). Selective Saccharomyces media containing ergosterol and Tween 80. Journal of the Institute of Brewing 84, 341-345.

Malkhas'yan, S. S., Nechaev, A. P., Gavrilova, N. N., Zotova, E. G. \& Doronina, O. D. (1983). Group and fatty acid composition of lipids of some yeast genera. Prikladnaya biokhimya i mikrobiologiya 19, 193-201. Applied Biochemistry and Microbiology (English Translation) 19, 154-161.

Nes, W. D., Adler, J. H. \& Nes, W. R. (1984). A structure-function correlation to fatty acids in Saccharomyces cerevisiae. Experimental Mycology 8, 55-62.
Patching, J. W. \& Rose, A. H. (1970). The effect and control of temperature. Methods in Microbiology 2 , 23-38.

Pilkington, B. J. \& Rose, A. H. (1988). Reactions of Saccharomyces cerevisiae and Zygosaccharomyces bailii to sulphite. Journal of General Microbiology 134, 2823-2830.

RANKINE, B. C. (1968). Formation of $\alpha$-ketoglutaric acid by wine yeasts and its oenological significance. Journal of the Science of Food and Agriculture 19, 624627.

Rankine, B. C. \& Pocock, K. F. (1969). Influence of yeast strain on binding of sulphur dioxide in wines and on its formation during fermentation. Journal of the Science of Food and Agriculture 20, 104-109.

RATTRAY, J. B. M. (1988). Yeasts. In Microbial Lipids, vol. 1, pp. 555-697. Edited by C. Ratledge \& S. G. Wilkinson. London: Academic Press.

RoBERTSON, R. N. (1983). The Lively Membranes. Cambridge: Cambridge University Press.

ROSE, A. H. (1987). Responses to the chemical environment. In The Yeasts, 2nd edn, vol. 2, pp. 540. Edited by A. H. Rose \& J. S. Harrison. London: Academic Press.

StratFord, M. \& Rose, A. H. (1985). Hydrogen sulphide production from sulphite by Saccharomyces cerevisiae. Journal of General Microbiology 131, 1417 1424.

Stratford, M. \& Rose, A. H. (1986). Transport of sulphur dioxide by Saccharomyces cerevisiae. Journal of General Microbiology 132, 1-6.

Stratford, M., Morgan, P. \& Rose, A. H. (1987). Sulphur dioxide resistance in Saccharomyces cerevisiae and Saccharomycodes ludwigii. Journal of General Microbiology 133, 2173-2179.

ThOMAs, D. S. \& DAVENPoRT, R. R. (1985). Zygosaccharomyces bailii - a profile of characteristics and spoilage activities. Food Microbiology 2, 157-169.

VAN DER MEER, W. (1984). Physical aspects of membrane fluidity. In Physiology of Membrane Fluidity, vol 1, pp. 53-71. Edited by M. Shinitzky. Boca Raton, Florida: CRC Press.

WARTH, A. D. (1985). Resistance of yeast species to benzoic and sorbic acids and to sulfur dioxide. Journal of Food Protection 48, 564-569.

WEDZICHA, B. L. (1984). Chemistry of Sulphur Dioxide in Foods. London: Elsevier Applied Science Publishers.

WICKerhaM, L. J. (1951). Taxonomy of yeasts. 1. Techniques of classification. United States Department of Agriculture Technical Bulletin no. 1029. Washington, DC: US Department of Agriculture. 